\title{
Digital Forensic Management System using Facial Recognition for Student's Participation and Registration on School Activities
}

\author{
C. Ratanaubol, P. Wannapiroon, P. Nilsook \\ King Mongkut's University of Technology North Bangkok Thailand
}

Received: July 7, 2020. Revised: November 30, 2020. Accepted: December 4, 2020.

\begin{abstract}
Face recognition technology is widely used in applications. But in some activities it may be too difficult to install the device and the registration boot. That requires both manpower and time, such as enrolling students to attend university activities. If you will use the face scanning system, one by one will waste a lot of time. The other method. It may be easy to falsify. Using digital imagery in student participation to solve problems by developing a system that can detect participants' faces in digital photographs obtained by taking still images and videos from several photographers. And collecting detailed pictures and videos throughout the event it is a digital proof to find the participants to verify their faces match with any student in the database. Who participate in that activity, the system will have Finding and comparing data of pre-recorded students' photographs and the algorithm would checks for duplicate data and records the activity in the database. Where users can specify category or activity name for later inspection.
\end{abstract}

Keywords - Digital forensics, Service learning, Activities tracking, Face Recognition, Face Search, Artificial Intelligent.

\section{INTRODUCTION}

In Asia University's activities are giving extra credits for student who participates The activities will show unity creativity self-sacrifice and morality, students must share their free time to participate in activities to pass the minimum requirement. Most university has thousands students, which makes it difficult for each activities to get participations name and ID. The traditional way we use are logbook which students collect stamp marks and sign in at participation boot.

The researcher has developed a system to solve problem which mention above. This system use face recognition method with artificial intelligence, this system can accept 2 kind of input which are still pictures and videos. This input data type make the system difference from other Digital Forensic Management System using for office attend in present market. This system can also use to detect participant's face remotely when social distancing is needed.There was no machine or technical support for on-site working like other system.

This research focus on usage of Digital Forensic Management System for student's participation and registration on school activities which most of university in Asia had difficulty to record student's participant. The system we use in this research also added new input methods which are an electronic video file, a synchronize video, and a Facebook video. 
The use of the system during the prevention of COVIC19 spreading, face detection algorithm and techniques in this research using OpenCV library and developed by Python Language, which has $90 \%$ in face detection accuracy. This system can also can use video recorded and photos from Social Media (Facebook).

\section{NEED ANALYSIS}

Since the students use activities participation as a part of evaluation in the provision of religious, artistic, cultural and social services, with a large number of students the error had occurred in some cases then student does not receive an assessment point [7], and in some situations, students gave their activity logbook to their friends to get the stamps [8] which is fault. The researcher collected 400 questionnaires on the use of information systems to collect points for participation in activities, instead of using papers.[12] There are 379 questionnaires returned which Constitute 94.75 percent. This research found that one of the biometric system which are face and fingerprint scans, the student agreed to use face recognition for 342 questionnaires, which is 85.5 percent Thus, researcher with the department of management collect sample of students' photos and activities photos and video for this research as show in Fig.1

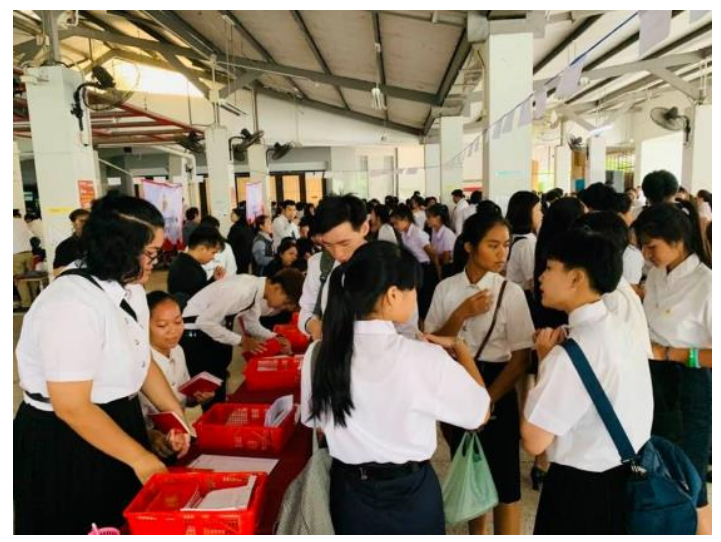

Fig. 1. Data collection for need analysis.

60\% Data collection for student's participation in the university are in video, and up to $80 \%$ of those are recorded by students and brought it on Social Media (as Facebook). This research developed the system that take advantage of social media by using those published pictures and videos.

\section{SYSTEM ANALYSIS AND DESIGN}

In designing the system, there are variables that the researcher designed, first, "digital evidence" which is facial recognition using on the Digital Forensic management System or DFMS. The large framework is to collect participation points to analysis [18]. Second, the activities' photos and videos at the university with students on them. Third, the researcher has arranged the students into an experimental group to get their face images in various angles and different emotions, there are 100 images to create the face pattern for each student, as show in Fig.3. Student's photos were linked to a student ID for each student then saved onto a database. All activities' picture and video were collected and saved on university activity photo file folder. After loading photos and video into program with activity name tag and date as we call "input", The system will generate a new record for this activity and date. After that each face on the image will be detected. Then the system will search can compare the input with the face set [21]. If a face matched, the system would be retrieved a corresponding Student ID and linked with the new record [24]. As show in fig.2

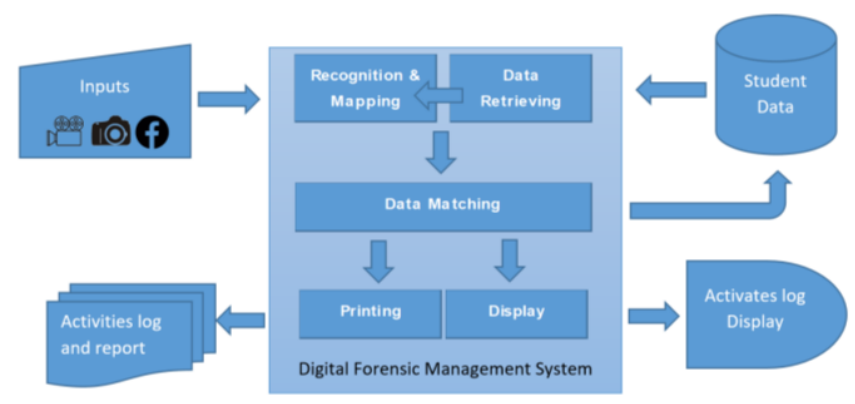


Fig. 2. System design diagram.
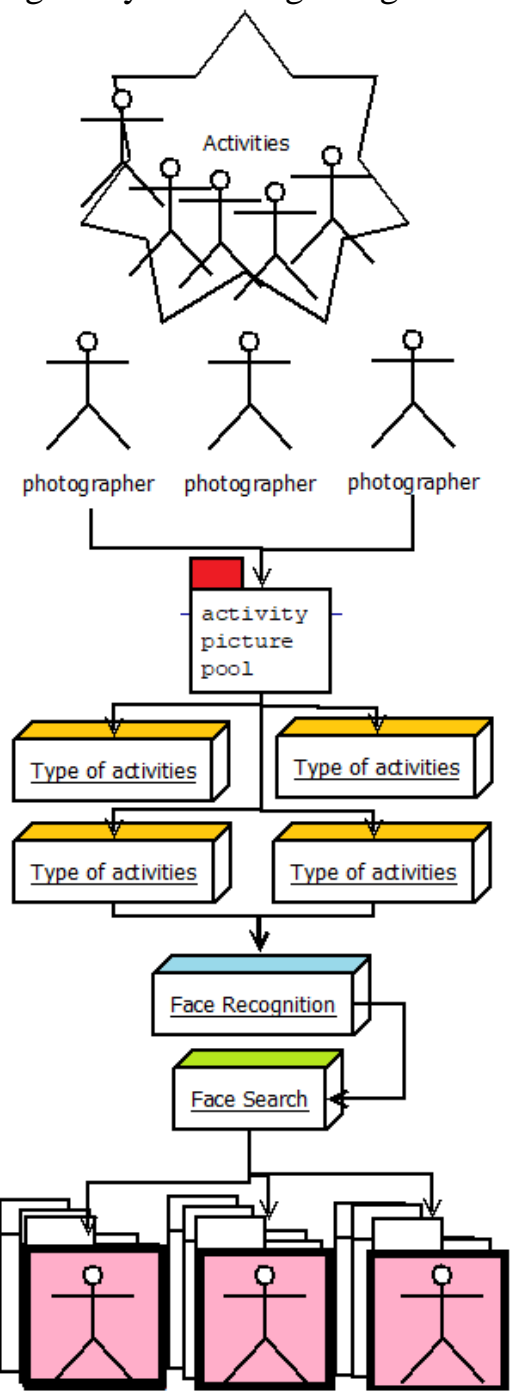

Student Data Set 1-3

Fig. 3. Show system flowchart.

\section{DIGITAL FORENSIC}

The evidence collection, search, analysis and presentation of digital evidence in computer and electronic devices such as files in computers, electronic devices, mobile phones Including digital evidence created from computer systems, etc. $[2,11]$ These data can be used to identify the offender to be evidence in the proceedings. In other words. Using the process which has already been established and accepted In order to identify, identify, preserve and retrieve digital information, which will be important for the investigation. Digital Forensics can be divided into 5 important steps as follows $[15,17]$

\section{A. Preservation}

The preservation of evidence that needs to be proven, which is the most important step in the process, because if the evidence data was accessed and changed a little, All of data will affect the credibility of the evidence.[19]

\section{B. Identification}

Specifying information about the evidence to be examined to enter the data analysis and analysis process.

\section{Extraction}

The extraction of necessary digital information. By using the forensics Image process for in-depth analysis.

\section{Interpretation}

The interpretation of digital evidence that has been verified.

\section{E. Documentation}

The preparation of witness's examination records.

Photographs at events held at the university are traces of one type of evidence that are abundant and can be used as evidence of student participation. [20, 23] Show in Fig.4.

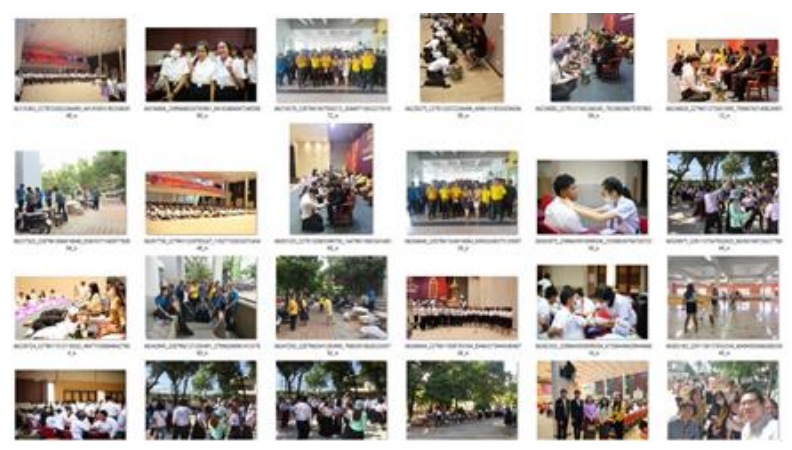

Fig. 4. Example of university activities participation pictures

\section{FACE RECOGNITION}

Face detection is the process of finding a person's face from an image or video then, the face image will be processed for the next step to make the detected face image easier to identify. Next step after face recognition is the process, which the detected face image is processed and processed from the face detection process. 
Comparing the appear face with the face database to determine which face the person detected, therefore the face recognition program is a system that analyzes the faces that are detected while walking through the camera to match the face of any person. [1] Comparing with the images in the database that has face recognition technology in addition to being used in security. It can also be applied to a variety of cases, such as shopping malls, car parks, schools, hospitals.[4] In this research, pawn face recognition technology is developed to find the faces of students in photos in the image database. To check for university activities by using a function called Face Search.

\section{SERVICE LEARNING}

The purpose of service learning is the essence of "Providing equal benefits to service providers and service providers, as well as providing equal service and learning." Volunteering for community service, internships and field studies is an example of either way or another, the main value of learning about services is because all students receive the same benefits as students. $[3,6]$ Acting on an equal level. The advantage material is these methods tend to focus on ensuring that students not only perform their duties but learn anything, whether they are human relations skills, their future work experience, or changes in the views of oneself and others. An important feature of the reflection service-learning program is the period of critical thinking that students do.[13] Many supporters in the field of teaching, reflection may be a symbol of learning that occurred among students. Janet Eyler and Dwight E. Giles are examples of this opinion in their book, Where's the Learning in Service-Learning? "Learning occurs through a cycle of actions and reflection, not just through the ability to count what is learned through reading and lecturing.".[14, 16]

\section{DIGITAL FORENSIC MANAGEMENT SYSTEM (DFMS)}

\section{Pictures and Data Pooling}

The researcher collected images for data analysis. There are 2 parts: 1st part, 100 sample faces for each students in experiment. This research collected data from 3 different group of student, which are 39 male students, 46 female students, and 35 male and female students who usually wear glasses or cosmetic. Therefore, the system will learn to recognize a total of 12,700 different photos.2nd part, the activities' pictures and videos were collected by the university photographer and research team from 10 different activities. There are 300 images in each activity. Therefore, in total of 10 activities, there will be 3,000 pictures as show in Fig.5.

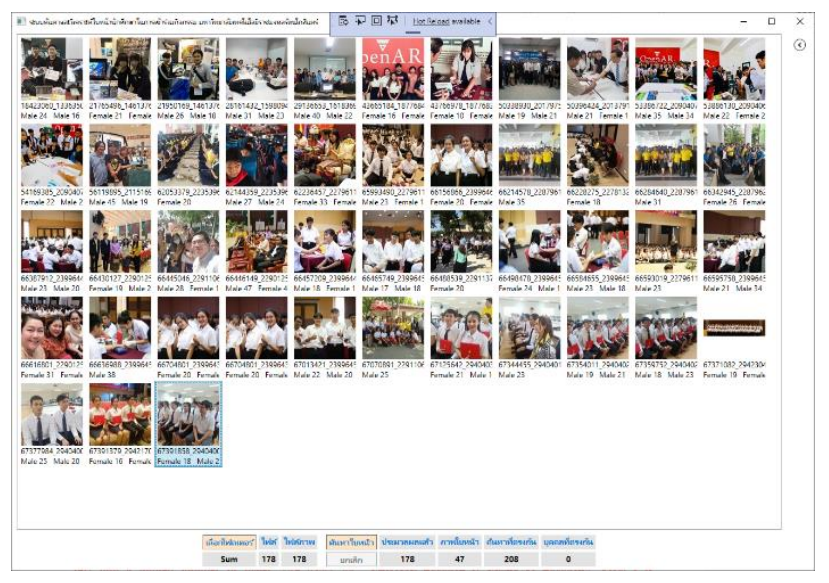

Fig. 5. Show pictures of university activities in the system.

\section{Face Detection and Recognition}

In the process of detecting faces from a photo, the researcher used an API service. There are 2 processes in this module. 1st process, computer program will scan to get faces on an image, then 2nd process, this program compared the faces in previous collected data and paired. The images can be bmp, gif, jpg or PNG format, the program created thumbnails for each image that were detected [5]. The program come with functions to specify age range, gender and student information. This part of system was developed in C \#.Net using Microsoft Visual Studio 2017.

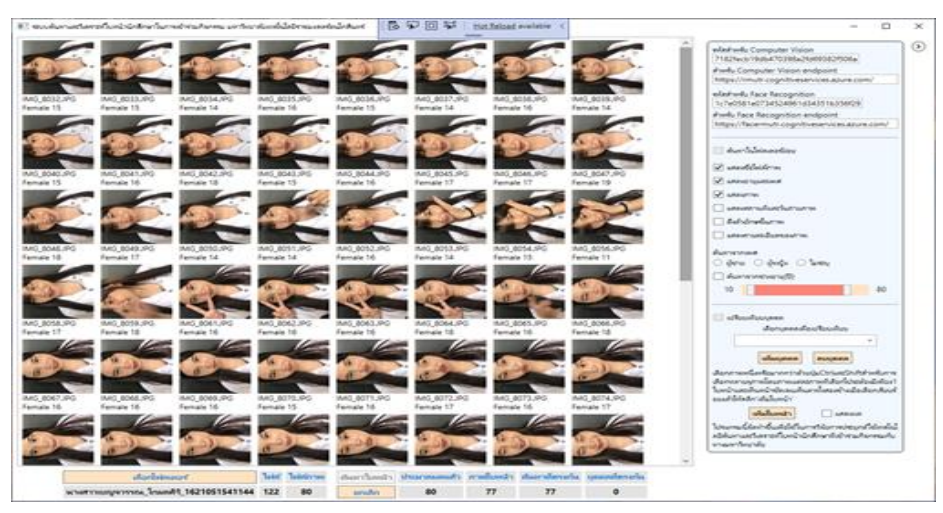

Fig. 6. Show the receipt of data of the lateral in the system. 
The student's photos and video was submitted into the system and be compared with sample photos. The activity photos were taken from all mobile phones [9], both vertical and horizontal images can be used to create image outline, show in Fig.6.

A problem we found with the sample photos is when we request for photos of different emotions and angles. Some students raised their hands up to their face which makes the gesture and recognition errors in the system. The researcher therefore needed to exclude new images from the sample group in the database. For the next reference, students need a photo guide or template for their sample photos, show in Fig.7.

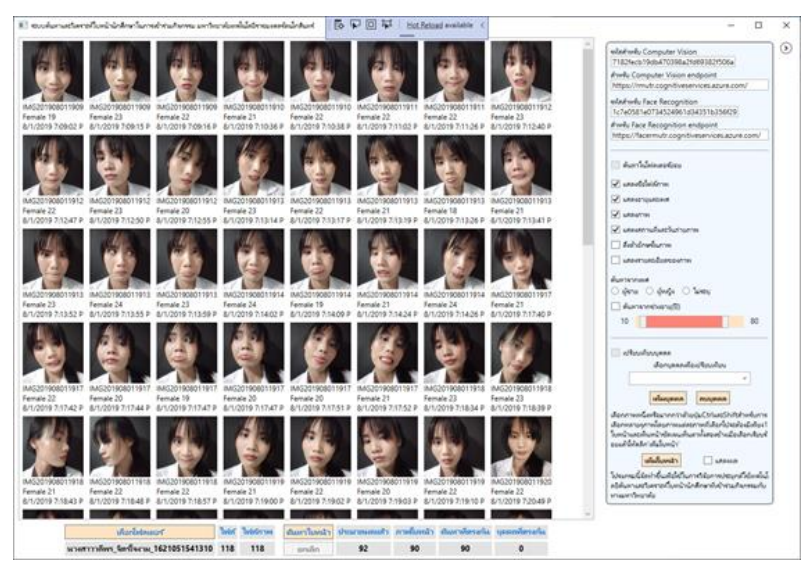

Fig. 7. Show the receipt of vertical face in the system.

\section{Face Searching and Matching}

The use of the Computer Vision, API gives developers chance to access to advanced algorithms for image processing and data return with function for uploading images or specifying image URLs in cloud computing. The Microsoft Computer using Vision algorithm that can analyze image content in different formats as it has builtin AI to learn to analyze image content in various formats.[10] The Computer Vision, API provides the most advanced algorithms for image processing and data output. For example, it can determine whether an image contains, adult content or detect all faces in an image. In addition, there are other features, such as the estimation of prominent colors and highlighting, classification image content and narrate them in complete English sentences. In addition, it is possible to create thumbnails for efficiency display.[22]
The face detection efficiency consists of two parts: $1^{\text {st }}$ Part, preparing students' face patterns by masking on the sample photos and put in a database ready for comparison. Part two: finding student's faces in the activity photo and video and pulling the pattern from the $1^{\text {st }}$ part to compare with them.

\section{Data Setting Result}

Every photo with student's activity participation can be collected as points and will be calculated at the end of semester. Only the students who were detect on the photo can enroll in the next semester, including the confirmation of registration to graduate.

Data processing module can only detect student's face from clear source only. This cause some students were not found in activity photos and videos, as they were not match with the template photos in the database due to being photographed at a distance, lost focusing or focus on landscapes and sceneries. Clearly the researcher informed the university's photographer and social media admins that the photos that give the best result were the photos and video with small group activities.

\section{TEST DATA APPLICATION AND RESULT}

The researcher found that after using this system the number of participants were increased and consistent up to 20-30 percent during the previous academic year. The number calculated from the 3 sample groups, a total of 121 students with 10 activities. The results were compared with last year attendance records. This system made students have an incentive to participate in the university activities. The data collect by satisfaction questionnaire and interviews. We believe that the activities will promote a scarification and the courage to socialize which is an important life skills. 


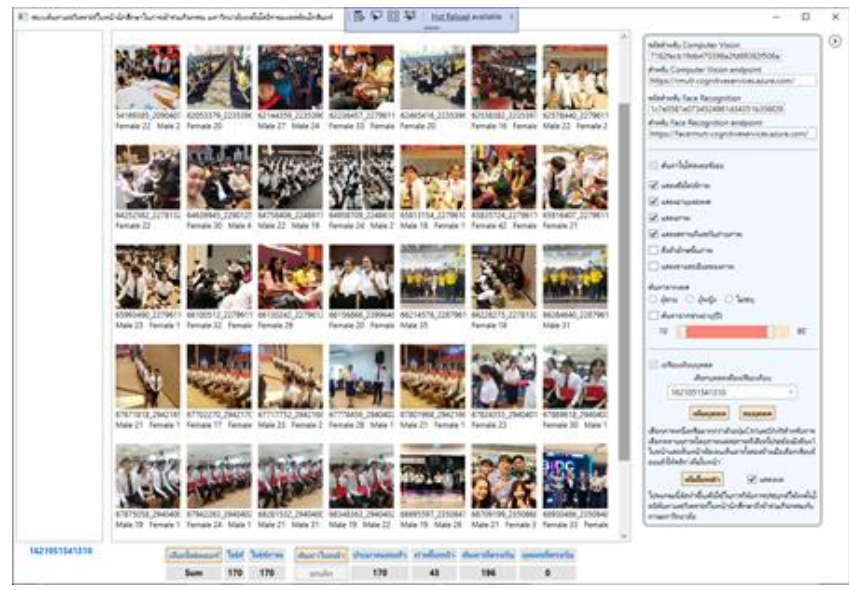

Fig. 8. Show face searches and recognition in the system.

The 10 activities which the students participated are in the photos taken by university staffs. The system recognized the faces and pulled the faces from samples database as shown in Fig.8. The students' participation was more and more consistent, the researchers found that after the students had attended and reached the activity hours but most of the students still participated in other activities.

\section{SOME COMMON LIMITATIONS}

Others problem was most photos took with the wide-angle lens and student face cannot be detected or detected with very low quality. Some student turned their face away from camera or refused to take photo because they were to shy Some students were wearing a surgical mask during COVID-19 and PM 2.5, which causes the system cannot detect their faces in some cases. The university's photographer resolved by taking photo in small groups and asked the participants to show their face. Some photos were taken from the back corner of the activity, the researcher asked for more photos from difference angles. Shown in Fig.9

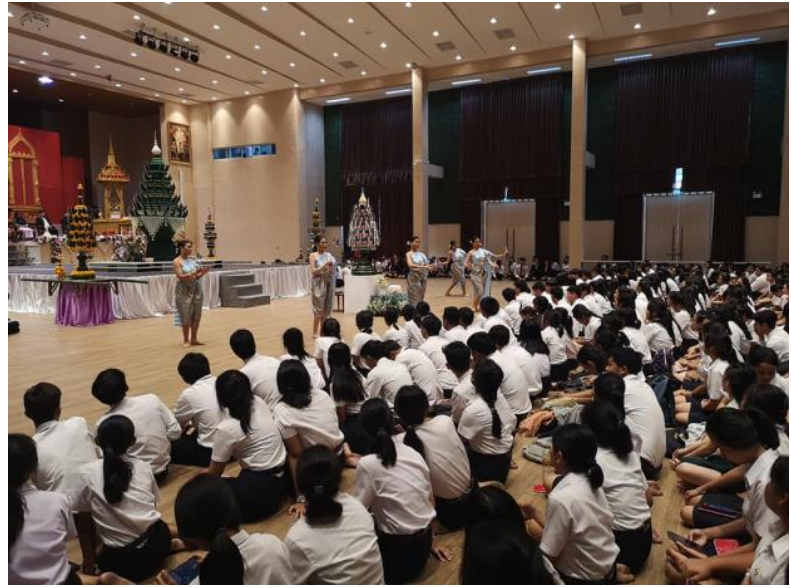

Fig. 9. Show pictures were taken from the back of the activity.

In some photos, the system is unable to detect faces and compare them with sample photos in the database due to being too small or low quality, shown in Fig.10.

One of the difficulty in taking pictures of a group of students was the photographer was unable to walk up close to take pictures from the front because sometimes there was a video recording but in this case we can use the videos.

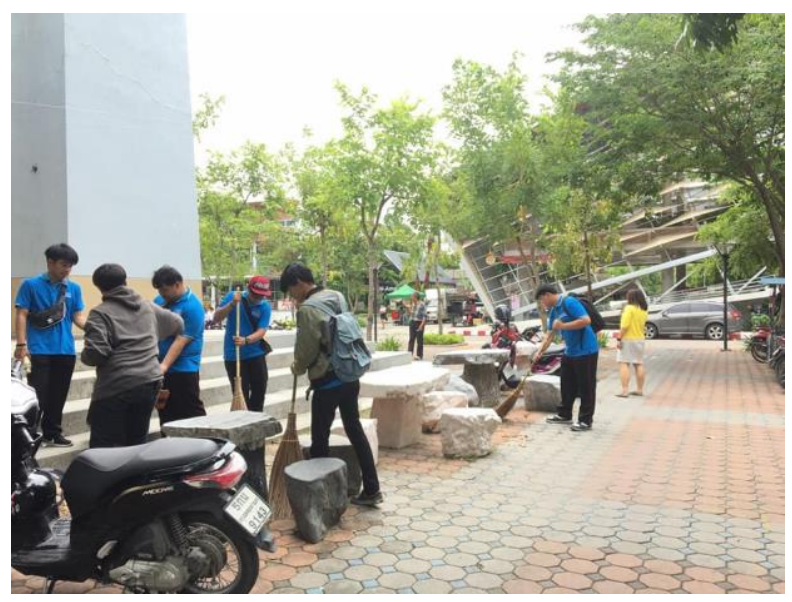

Fig. 10. Show pictures of activities too wide.

During the previous academic year, the COVID-19 pandemic occurs students and staff were wearing a surgical mask, which makes it impossible to retrieve a student's face in the image as shown in Fig.11. 


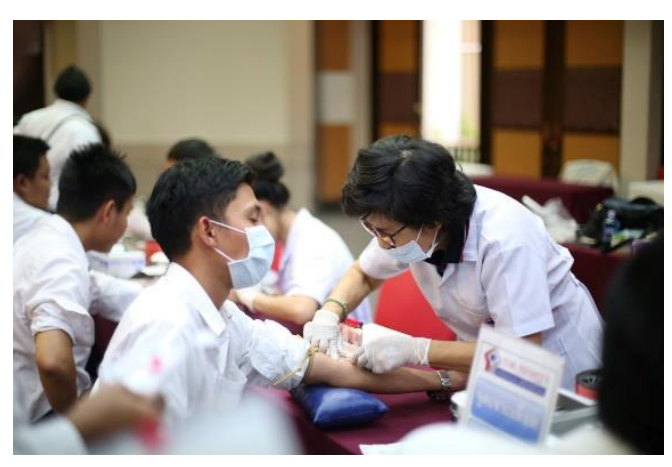

Fig. 11. Show pictures of activities that have concealed faces.

Students who participate in this research were divided into two groups and activity photos were taken by the two groups of university photographer for both sample photos and activities 'photos. This research took 100 images per activity per student group. In Table I, shows the total of detected photos and undetected photos from both sets.

TABLE I: Data classification

\begin{tabular}{|c|c|c|c|c|c|c|}
\hline \multirow{3}{*}{ Activities } & \multicolumn{6}{|c|}{ Participation's records } \\
\hline & \multicolumn{3}{|c|}{ logbooks } & \multicolumn{3}{|c|}{$\begin{array}{lr}\text { Digital Forensic } \\
\text { Management System }\end{array}$} \\
\hline & Set1 & Set2 & AVG & Set 1 & Set2 & AVG \\
\hline 1 & 20 & 25 & 22.5 & 81 & 92 & 86.5 \\
\hline 2 & 26 & 33 & 29.5 & 89 & 94 & 91.5 \\
\hline 3 & 35 & 34 & 34.5 & 94 & 98 & 96 \\
\hline 4 & 31 & 21 & 26 & 94 & 95 & 94.5 \\
\hline 5 & 22 & 22 & 22 & 96 & 97 & 96.5 \\
\hline 6 & 34 & 27 & 30.5 & 97 & 99 & 98 \\
\hline 7 & 12 & 38 & 25 & 89 & 91 & 90 \\
\hline 8 & 23 & 44 & 33.5 & 95 & 89 & 92 \\
\hline 9 & 39 & 34 & 36.5 & 97 & 96 & 96.5 \\
\hline 10 & 37 & 31 & 34 & 90 & 94 & 92 \\
\hline Avg & 27.9 & 30.9 & 29.4 & 92.2 & 94.5 & 93.35 \\
\hline \multirow{3}{*}{$\begin{array}{l}\text { T-test } \\
\text { (2-Tails) }\end{array}$} & \multicolumn{4}{|c|}{ logbooks set 1 and set 2} & 0.23 & Sig* \\
\hline & \multicolumn{2}{|c|}{$\begin{array}{l}\text { Digital } \\
\text { Management } \\
\text { and set2 }\end{array}$} & \multicolumn{2}{|c|}{\begin{tabular}{lr}
\multicolumn{2}{r|}{ Forensic } \\
System & set1
\end{tabular}} & 0.13 & Sig* \\
\hline & \multicolumn{4}{|c|}{$\begin{array}{l}\text { AVG logbook } \\
\text { Digital Forensic }\end{array}$} & 0.00 & Sig* \\
\hline
\end{tabular}

From Table 1 above showed that, there were 2 logbook stamp boots setup in the activities. There were only 29.40 average of student attended the activities. When our university used Digital Forensic Management System, there were 93.35 average of student attended the activities. 2 photographer teams took 2 sets of photo just to see if our system were accurate. This statistic shown that there were significantly different between using the logbook and the system at 0.05 .

The benefit of this system, student's comment show that digital photographic can record the date and time automatically. The system can prevent misinformation or fake records. Students can share their photo on the social media and use them as reference for employment after graduation which is important in Asia.

The old tradition logbook system for participating in activities cannot be used as the same way for future work. This is one reason that motivated students to join more activities as well as having the courage to present oneself more to the public.

The process of checking activity participation using student activity log book. At the first semester for firstyear students, approximately one thousand to two thousand students will be summoned at the same time. The activity log (red book) will be distributed for students to fill in and counting the hours so that students can calculate how much time they have left to attend shown in Fig.12. Normally the students have to attend and participate in university activities at least 50 hours per semester. 


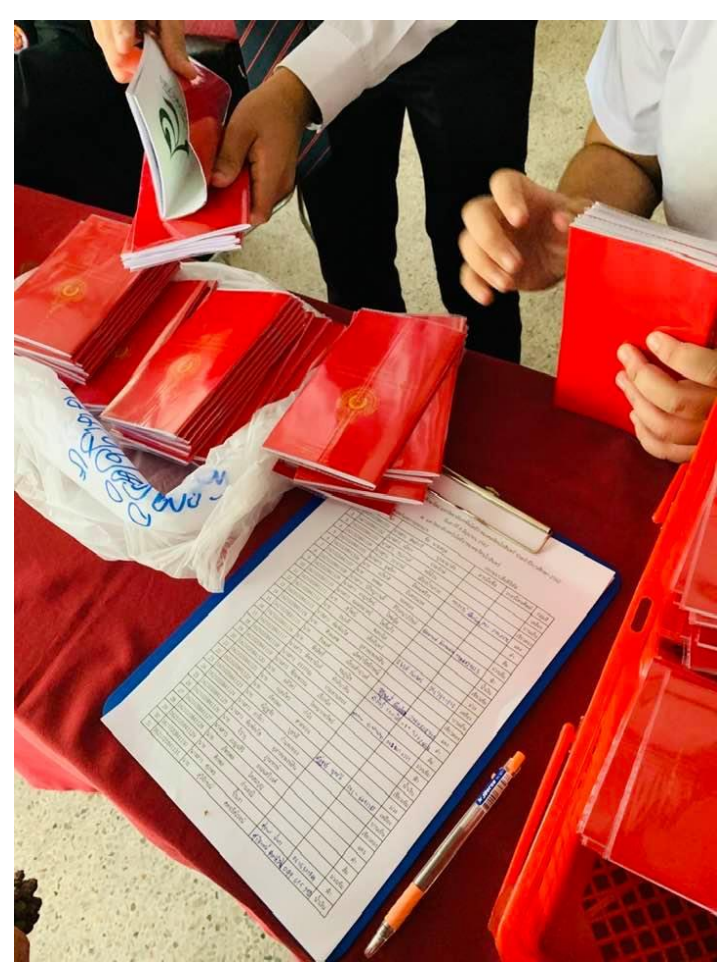

Fig. 12. Sample of activity logbook.

The program use computer resources efficiently. It needs only $256 \mathrm{MB}$ of RAM on $1.6 \mathrm{GHz}$ CPU speed. The computer must have GPU image processing, without any special hardware installation. Shown in Fig.14.

The 1st version, the program can accept photo input in JPG, BMP and PNG for sample and mapping. Also can detect faces from activity photos in JPG and BMP then generate an input in database.

The 2nd Version, this program can detect face on the real time video and record the student's face pattern from the video right in student activity evens. The digital video was obtained from the university's Information Service Center. Shown in Fig.13.

The 3rd Version, the system can analyze videos sent from various social media platforms with an accuracy of up to 80 to 90 percent. The videos will reveal the faces more clearly than the still picture.

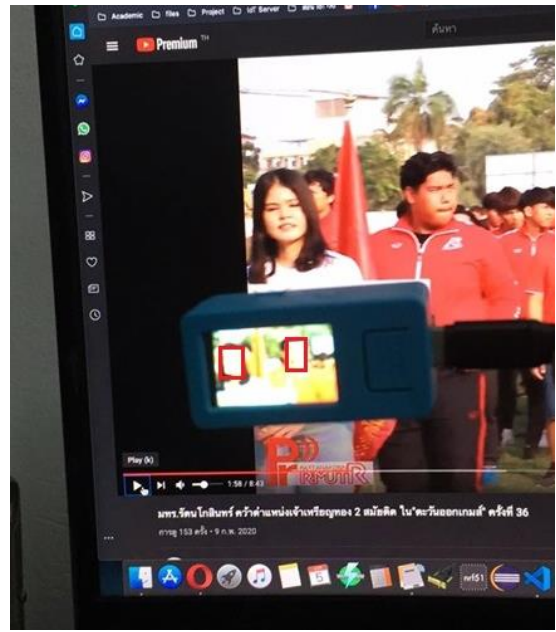

Fig. 13. Show face recognition detection on monitor.

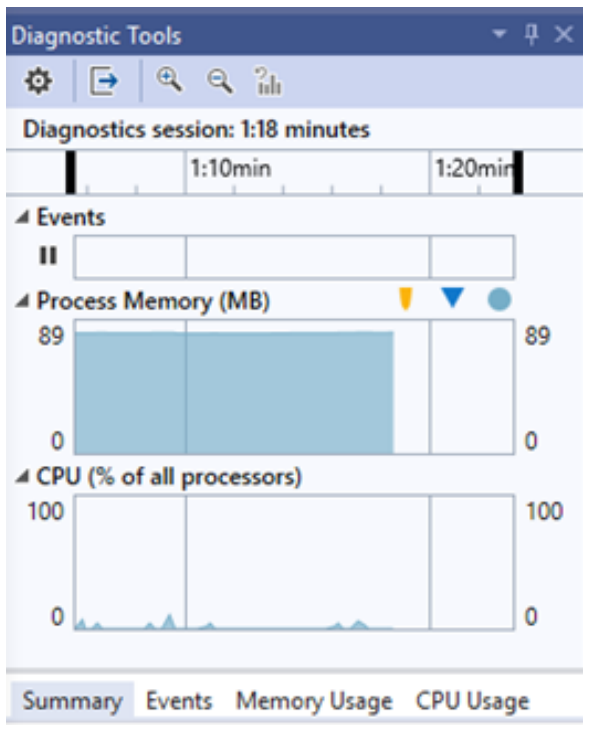

Fig. 14. Show images of resource usage while searching for faces.

Face detection based on the face that appears on the image, then compared with the corresponding face data, names and other information can be identified. This is an important prerequisite of applications that deal with using filters or editing faces in images search optimization and comparison. 


\section{CONCLUSION}

The research conclusions are divided into 5 parts.

The 1st part we interviewed students and found that activity logbook was allowing students to mislead university officers and got stamp without attending. Second, in system analysis and design process the researcher inquired that students always take photos in university's activities, so they can to share on social media with friends. They also like to see their photo on university's photo online photo albums as university staff always take pictures of activities for executive reports. The 3rd parts, during system developed and deployed, the researcher found this system motivated student to attend more activity and the system has $80-90 \%$ detected students' face and retrieved data accurately from the database. There were significantly different between using the logbook and the system at 0.05 The 4th part, show that there were only minor problem with this system such as unclear or lost focus or there was no students in the photos. And the 5th part, it was found that the participation in the activity was continuous and exceeded the minimum required for students to enter for 50 hours significantly. Next, the researchers predict that the system can push students to participate in activities continuously and realize the importance of social service activities and making sacrifices themselves for the benefit of others. This research will continue study on new face detection algorithm combine with other recognition method to provide nearly 100 percent accurate for the future. The new feature is now under development is Facebook API which student can link their Facebook with university's system and retrieve their photos wither certain caption relate to activities .

\section{Conflict of Interest}

The author declares that in the development of this research. The author has tried and written the article until it has been published. There is no conflict of interest with anyone or any organization at all.

\section{Author Contributions}

Chanate Ratanaubol is a researcher in this project. This author has studied, analyzed, designed, developed the system as well as tested this system for this research. Panita Wannapiroon and Prachyanun Nilsook are advisers of this research. Both authors have suggested the development and modification of the system for accuracy and good system requirements. As well as driving the development of this system to be used in universities.
Acknowledgment

I cannot express enough thanks to my committee for their continued support and encouragement by Dr. Kongkiat Hirankerd, my committee.

\section{References}

[1] H. Zhang, J. Yang, J. Qian and W. Luo, "Nonconvex relaxation based matrix regression for face recognition with structural noise and mixed noise," Neurocomputing, vol. 269, pp. 188-198, 2017.

[2] J. Wang, T. Li, Y. Q. Shi, S. Lian and J. Ye, "Forensics feature analysis in quaternion wavelet domain for distinguishing photographic images and computer graphics," Multimedia Tools and Applications, vol. 76, no. 22, pp. 23721-23737, 2017.

[3] A. Velicanu, I. Lungu, V. Diaconita and C. Nisioiu, "The 9 th International Scientific Conference eLearning and software for Education," pp. 380386, 2013.

[4] S. Soltanpour, B. Boufama and Q. M. Jonathan $\mathrm{Wu}$, "A survey of local feature methods for 3D face recognition," Pattern Recognition, vol. 72, pp. 391406, 2017.

[5] K. Shang, Z. H. Huang, W. Liu and Z. M. Li, "A single gallery-based face recognition using extended joint sparse representation," Applied Mathematics and Computation, vol. 320, pp. 99$115,2018$.

[6] M. Salam, D. N. Awang Iskandar, D. H. A. Ibrahim and M. S. Farooq, "Service learning in higher education: a systematic literature review," Asia Pacific Education Review, vol. 20, no. 4, pp. 573593, 2019.

[7] I. V. Romanova, L. N. Ponomarenko, A. N. Kibishev and M. M. Susloparova, "Civil values awareness formation in high school students within the educational process," European Journal of Contemporary Education, vol. 7, no. 3, pp. 541$553,2018$. 
[8] L. Pham, Y. B. Limbu, T. K. Bui, H. T. Nguyen and H. T. Pham, "Does e-learning service quality influence e-learning student satisfaction and loyalty? Evidence from Vietnam," International Journal of Educational Technology in Higher Education, vol. 16, no. 1, 2019.

[9] B. S. Oh, K. Oh, A. B. J. Teoh, Z. Lin and K. A. Toh, "A Gabor-based network for heterogeneous face recognition," Neurocomputing, vol. 261, pp. 253-265, 2017.

[10] L. Nanni, A. Lumini and S. Brahnam, "Ensemble of texture descriptors for face recognition obtained by varying feature transforms and preprocessing approaches," Applied Soft Computing Journal, vol. 61, pp. 8-16, 2017.

[11] Z. f. Liao, Y. Li, Y. Peng, Y. Zhao, F. f. Zhou, Z. n. Liao, S. Dudley and M. Ghavami, "A semanticenhanced trajectory visual analytics for digital forensic," Journal of Visualization, vol. 18, no. 2, pp. 173-184, 2015.

[12] D. Kloss, "the Experiences of Progressive School Students," Journal of Unschooling and Alternative Learning, vol. 12, no. 24, p. 24, 2018.

[13] R. A. Khan, M. S. Ahmad and R. U. Khan, "ServiceLearning for Youth Leadership," Applied Research in Quality of Life, 2019.

[14] S. Ketonen-Oksi, "Creating a shared narrative: the use of causal layered analysis to explore value cocreation in a novel service ecosystem," European Journal of Futures Research, vol. 6, no. 1, 2018.

[15] W. Y. Jo, H. Chang and T. Shon, "Digital forensic science approach by file recovery research," Journal of Supercomputing, vol. 74, no. 8, pp. 37043725, 2018.

[16] F. P. Held, C. Roberts, M. Daly and C. Brunero, "Learning relationships in community-based service-learning: A social network analysis," $B M C$ Medical Education, vol. 19, no. 1, pp. 1-10, 2019.

[17] J. Harron, J. Langdon, J. Gonzalez and S. Cater, "DIGITAL FORENSICS: Using Smartphones to Explore Metadata in a Simulated Criminal Case," The Science Teacher, vol. 84, no. 8, p. 31, 2017.
[18] E. A. Foreman, M. Retallick and S. Smalley, "Changing Demographics in College of Agriculture and Life Sciences Students," NACTA Journal, vol. 62, no. 2, p. 161, 2018.

[19] A. Cohen, "Analysis of student activity in websupported courses as a tool for predicting dropout," Educational Technology Research and Development, vol. 65, no. 5, pp. 1285-1304, 2017.

[20] P. Cigoj and B. J. Blažič, "An advanced educational tool for digital forensic engineering," International Journal of Emerging Technologies in Learning, vol. 11, no. 3, pp. 15-23, 2016.

[21] K. Begley, K. O’brien, K. Packard, S. Castillo, A. R. Haddad, K. Johnson, K. Coover and A. Pick, "Impact of interprofessional telehealth case activities on students' perceptions of their collaborative care abilities," American Journal of Pharmaceutical Education, vol. 83, no. 4, pp. 474482, 2019.

[22] S. A. Angadi and V. C. Kagawade, "A robust face recognition approach through symbolic modeling of Polar FFT features," Pattern Recognition, vol. 71, pp. 235-248, 2017.

[23] S. Alqahtany, N. Clarke, S. Furnell and C. Reich, "A forensic acquisition and analysis system for IaaS," Cluster Computing, vol. 19, no. 1, pp. 439453, 2016.

[24] E. Akbar, R. A. Farooq and R. Tabassum, "Effect of Fishbowl Activity on the Academic Achievements of Secondary School Students," Bulletin of Education and Research, vol. 40, no. 1, pp. 11-18, 2018.

Chanate Ratanaubol is a candidate doctor degree at the Division of Information and Communication Technology for Education, Faculty of Technical Education, King Mongkut's University of Technology, North Bangkok (KMUTNB), Thailand. He currenly work in the field of Business Information Technology, Faculty of Business Administration, Rajamangala University of Technology Rattanakosin. (e-mail: s5902052956029@email.kmutnb.ac.th) 
Panita Wannapiroon in as associate professor at the Division of Information and Communication Technology for Education, Faculty of Technical Education, King Mongkut's University of Technology, North Bangkok (KMUTNB), Thailand. Presently, she works in the field of ICT in education. She is member of the professional societies, the Apec Learning Community Builders, Thailand (ALCoB) and the Association for Educational Technology of Thailand (AETT). (e-mail : panitaw@kmutnb.ac.th)

Prachyanun Nilsook is an associate professor at the Division of Information and Communication Technology for Education, Faculty of Technical Education, King Mongkut's University of Technology, North Bangkok (KMUTNB), Thailand. He currently works in the field of ICT for education. He is a member of the professional society, the Association for Educational Technology of Thailand (AETT). (e-mail : prachyanunn@kmutnb.ac.th)

\section{Creative Commons Attribution License 4.0 (Attribution 4.0 International, CC BY 4.0)}

This article is published under the terms of the Creative Commons Attribution License 4.0

https://creativecommons.org/licenses/by/4.0/deed.en_US 